05

\title{
Дестабилизация внедрения высокоскоростной струи в хрупких материалах
}

\author{
(C) Б.В. Румянцев
}

Физико-технический институт им. А.Ф. Иофрфе РАН, 194021 Санкт-Петербург, Россия

E-mail: brum@mail.ioffe.ru

Поступило в Редакцию 14 сентября 2018 г.

В окончательной редакции 14 сентября 2018 г.

Принято к публикации 25 октября 2018 г.

Проанализированы результаты внедрения в хрупкие материалы (керамики и стекло) металлической высокоскоростной струи со скоростью $3-7 \mathrm{~km} / \mathrm{s}$. Приведены данные по дестабилизации струи в результате реакции хрупкого материала на высокоскоростное внедрение. В гидродинамическом приближении построена обобщенная зависимость эффективности поглощения высокоскоростной струи от предела прочности к изгибу хрупкого материала.

DOI: 10.21883/JTF.2019.05.47469.337-18

\section{Введение}

В отличие от металлов внедрение металлической высокоскоростной струи (ВСС) в хрупкие материалы (керамики, стекла, горные породы) осложняется взаимодействием с каверной в преграде [1-9]. Наблюдаемое эффективное поглощение струи объяснялось повышенным прочностным сопротивлением хрупких материалов (ХМ) $[7,8,10]$. Прямые рентгенографические исследования $[2,11,12]$ показывают, что внедрение в XМ сопровождается разрушением высокоскоростного ударника. В то же время отдельные измерения кинетики внедрения не позволяли выявить особенности взаимодействия на траектории движения металлической струи в ХМ.

В результате систематических исследований $[2,5,13,14]$ было показано проявление радиального схлопывания каверны на траектории движения струи в ХМ. Анализ этих результатов позволил расширить понятие о реакциях твердых тел на высокоскоростное внедрение:

- первичные - в зоне внедрения: инерционное и деформационное сопротивление с учетом прочности и сжимаемости;

- вторичные - взаимодействие каверны с внедряющейся струей.

Взаимодействие удлиненного ударника с хрупким материалом является примером, когда первичная реакция материала преграды дестабилизирует дальнейшее его внедрение.

С целью изучения дестабилизации внедрения в настоящей работе исследуется кинетика проникания возмущенной взаимодействием с каверной ВСС. На основании обобщения экспериментальных результатов рассматривается оценка максимальных возможностей по поглощению ВСС в ХМ.

Высокоскоростная струя со скоростью от 7 до $1.5 \mathrm{~km} / \mathrm{s}$ образуется при детонации заряда взрывчатого вещества
(BB) с металлическим тонкостенным конусом. При оптимальных соотношениях: масс ВВ и конуса, углов конуса и детонационного фронта, диаметра конуса и фокусного расстояния градиент скорости по длине струи обеспечивает пробитие металлической преграды на глубину до 5-6 начальной длины струи $[1,2,13]$.

Исследования влияния дестабилизации на внедрение проводились при нормальном воздействии струи на преграду. В случае металлической преграды процесс пробития носит квазистационарный характер (рис. 1) и ограничен длиной струи, разрывом на отдельные элементы при определенном растяжении [2], радиальным расхождением элементов и условиями истечения в конце внедрения - критической скоростью $\left(V_{\mathrm{cr}}\right)$ [13].

Ниже будет показано, что при таких возможностях ВCС достаточно уязвима к действию возмущающих факторов. Для выявления особенностей в кинетике внедрения необходимо сравнение экспериментальных результатов с базовым расчетом в гидродинамическом струйном приближении $[2,15]$.

Движение каждого элемента струи от момента зарождения при схлопывании воронки под действием продуктов взрыва до образования каверны в преграде определяется по формулам гидродинамической теории кумуляции:

$$
\begin{gathered}
W_{i}=f\left(M_{i H e} / m_{i}, D, \alpha_{i D f}\right), \\
V_{i}=W_{i} \operatorname{ctg}\left(\alpha_{i} / 2\right), \\
d l_{i}=d l_{0}\left(1+Z_{i} d V_{i} / V_{i}\right),
\end{gathered}
$$

где $f\left(M_{i H E} / m_{i}, D, \alpha_{i D f}\right)$ - зависимость скорости $W_{i}$ метания $i$-го элемента металлической воронки от соотношения масс-взрывчатого вещества $M_{i H E}$ и элемента воронки $m_{i}$, скорости детонации взрывчатого вещества $D$, угла подхода детонационного фронта $\alpha_{i D f} ; V_{i}-$ 


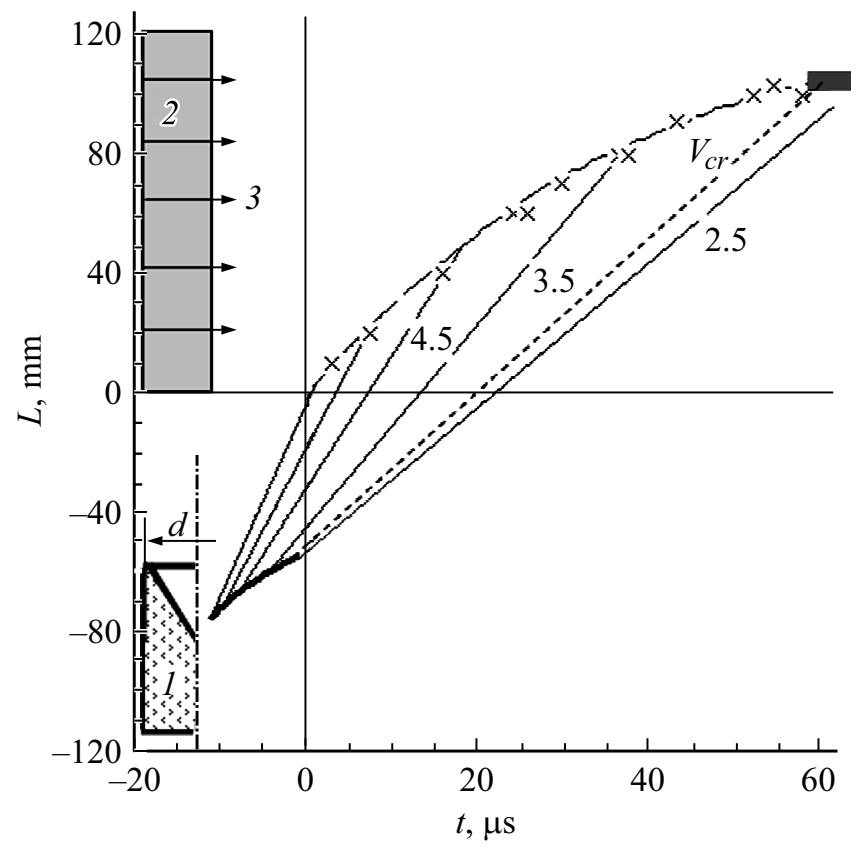

Рис. 1. Схема эксперимента, $L-t$ диаграмма формирования, движения и внедрения элементов струи в сталь: 1 - заряд ВВ массой $40 \mathrm{~g}$ с медной воронкой с диаметром в основании $d=20 \mathrm{~mm} ; 2$ - слои материала преграды на фокусном расстоянии $60 \mathrm{~mm} ; 3$ - контактные датчики фиксирования времени проникания. Расчетные траектории: формирования струи (сплошная полужирная кривая), движения элементов струи с обозначением скорости в $\mathrm{km} / \mathrm{s}$ (прямые линии), внедрения струи в преграду (штриховая кривая). $X-$ экспериментальные времена проникания медной струи в сталь St40. Серая область - конечная глубина внедрения. Пунктирная прямая скорость струи в конце внедрения $V_{\text {cr. }}$.

скорость элемента струи $d l_{0}$, образовавшегося при схлопывании со скоростью $W_{i}$ конической части кумулятивной облицовки под углом $\alpha_{o}$ к оси; $d l_{i}-$ длина элемента струи после прохождения расстояния $Z_{i}$ от области формирования до внедрения и растяжения под действием градиента скоростей $d V_{i}$.

Расчет производится в гидродинамическом осевом приближении численным интегрированием уравнения внедрения.

Связь между скоростью элемента струи $V_{j}$ и скоростью его внедрения в преграду $U$ определяется модифицированным уравнением Бернулли [15]:

$$
R_{t}+\rho_{t} U^{2} / 2=R_{j}+\rho_{j}\left(V_{j}-U\right)^{2} / 2
$$

где $\rho_{j}, R_{j}$ и $\rho_{t}, R_{t}$ - плотность и динамическое сопротивление деформированию материалов струи (индекс $j$ ) и преграды (индекс $t$ ) соответственно. Значения $\rho_{j}, R_{j}$ для медного струи принимались равными $8900 \mathrm{~kg} / \mathrm{m}^{3}$ и $0.45 \mathrm{GPa}$. Динамическое сопротивление материала преграды находилось из описания экспериментальных результатов на квазистационарном участке внедрения сплошной части струи.
Глубина $d L_{i}$ и время $d t_{i}$ внедрения элемента струи $d l_{i}$ определяются

$$
\begin{gathered}
d L_{i}=d l_{i} U_{i} /\left(V_{i}-U_{i}\right), \\
d t_{i}=d L_{i} / U_{i} .
\end{gathered}
$$

В результате численного интегрирования по высоте металлической воронки заряда 1 получаются траектории (рис. 1): формирования струи (сплошная кривая), движения элементов струи (прямые линии) и проникания в преграду 2 (штриховая линия).

Проникание сплошной струи имеет непрерывный (квазистационарный) характер. Введение предельного растяжения для материала струи позволяет описать внедрение КС отдельных хвостовых элементов. Тарировка расчета производится по данным кинетики внедрения медной струи в металлы [13]. Согласование достигается при значении предельного растяжения, равном 13, против 15-17 для более качественно изготовленных воронок $[2,15]$. Окончание внедрения совпадает с определением $V_{\text {cr }}[2,13,15]$ и отражает влияние динамического сопротивления материала преграды.

В отличие от металлов при исследовании действия ВВС на ХМ на экспериментальной траектории внедрения и сравнении с расчетом были выявлены следующие особенности [5]. Начальный участок траектории внедрения имел непрерывный характер и совпадал с гидродинамическим расчетом с учетом динамического сопротивления деформированию преграды. Далее фиксировалась приостановка внедрения и возобновление в неустойчивом виде.

Эти особенности определены тем, что при внедрении головных элементов высокоскоростной струи в хрупкие материалы в зоне внедрения реализуется откол и откольные массы воздействуют на последующие части струи. Преодоление области взаимодействия струи и материала каверны приводит к вторичному расходу и дестабилизации дальнейшего внедрения. Измеренные времена проникания на этой стадии имеют „кажущийся“ разброс и всегда больше расчетных.

Введение в расчет времени задержки схлопывания каверны $\left(t_{i n}\right)$ позволило описать вторичное внедрение по схлопнувшемуся материалу преграды; восстановление первичного проникания с прочностью или без в зависимости от влияния волнообмена от границ конкретной преграды. Сопоставление с экспериментом свидетельствует, что расчет в гидродинамическом приближении дает минимальную оценку времени и максимальную глубину внедрения без учета дестабилизации ВВС в результате взаимодействия с каверной в ХМ.

Радиальное взаимодействие каверны со струей является отличительным признаком внедрения в высокомодульные хрупкие материалы и в основном определяет их повышенную струегасящую способность. Это поведение ХМ, найденное экспериментально и получившее объяснение дестабилизацией внедрения $\mathrm{BBC}$, нашло 
$a$ $b$
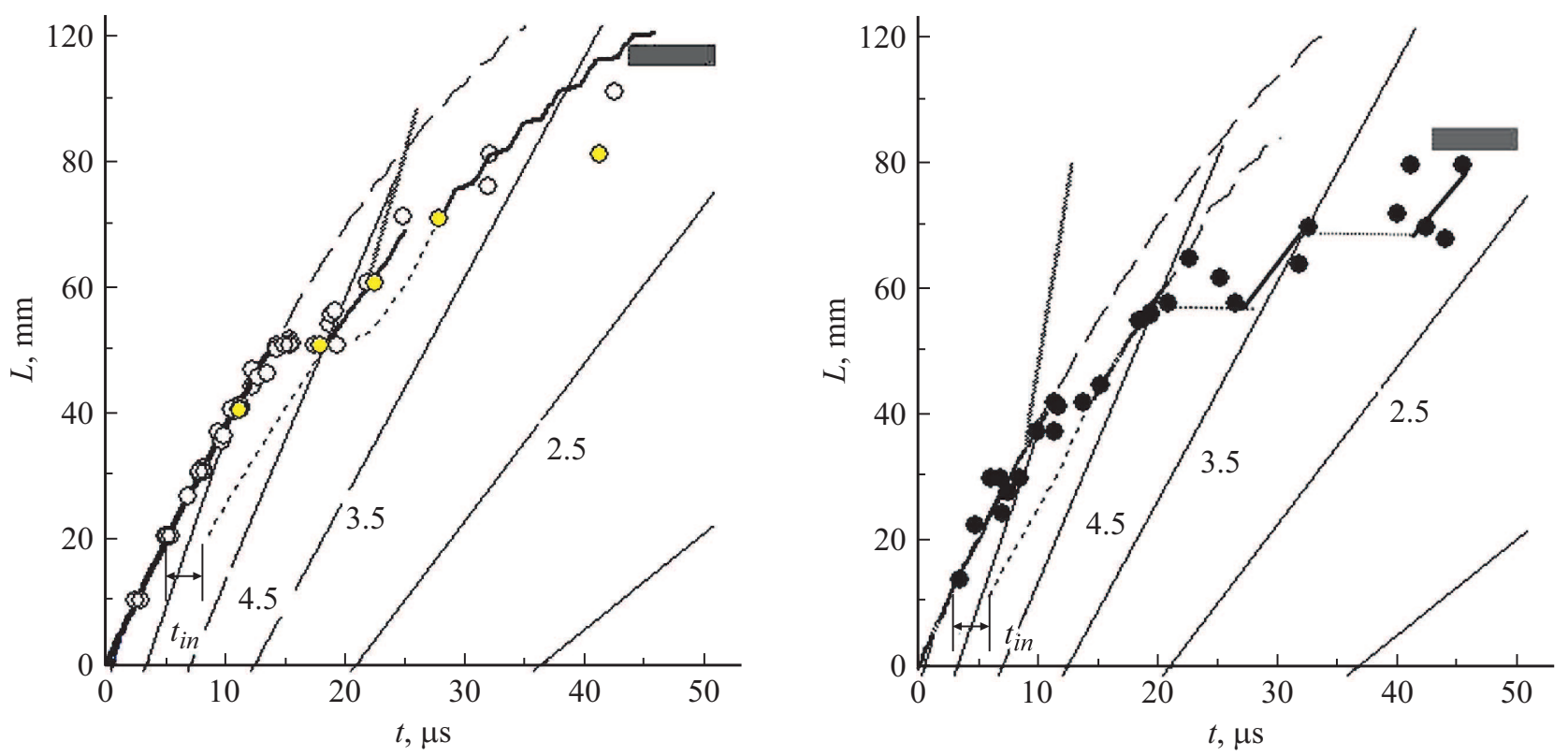

Рис. 2. Кинетика внедрения медной струи в стекло $(a)$ и карбид бора $(b)$. Сплошная и пунктирная кривые - первичное и вторичное моделирование внедрения. Размытая прямая - траектория боковой волны разгрузки после опережения зоны внедрения. Точки - экспериментальное определение времен проникания. $t_{i n}$ - задержка схлопывания каверны. Остальное - как на рис. 1.

широкое применение в защите от высокоскоростного удара.

Очевидно, что чем больше прочностные характеристики ХМ, тем больше скорость схлопывания откольных фрагментов каверны и сильнее будет воздействие на струю. В то же время откольная прочность не может быть рекомендована в качестве критерия отбора ХМ для защиты от высокоскоростного ударника, в виду сложности получения достоверных значений даже в условиях одномерного нагружения [16]. Определение времени задержки схлопывания каверны [2,5,12-14] позволяет оценить сравнительный уровень откольной прочности ХМ в условиях разгрузки в зоне внедрения. Более достоверным и значимым является определение длины головной части струи, отсекаемой за время задержки и формирующей каверну, по длине которой реализуется радиальное возмущение последующих участков струи и дальнейшую историю внедрения. По согласованию экспериментальных времен внедрения головной части ВВС с расчетом определяется динамическое сопротивление деформированию $R_{t}$ для ХМ $[13,14]$. Однако этих параметров недостаточно, чтобы предсказать возможности ХМ по поглощению ВСС.

\section{Кинетика внедрения высокоскоростной струи в хрупкие материалы}

За последние годы качество изделий из керамики значительно улучшилось, выросли прочностные характеристики и стабильность при хранении. Это отразилось на увеличении стойкости защитных устройств с применением ХМ.

В настоящей работе уже известные данные $[5,13,14]$ дополнены изучением внедрения ВСС в карбид бора, имеющего максимальные прочностные показатели при минимальной плотности в ряду промышленных керамик (табл. 1). Кинетика внедрения в карбид бора медной струи производилась по схеме, представленной на рис. 1. При детонации заряда 1 формировалась медная струя с градиентом скорости от 6.5 до $1.5 \mathrm{~km} / \mathrm{s}$, которая внедрялась в стальную преграду средней твердости на глубину $118 \mathrm{~mm}$. Разрыв струи на элементы начинался при скорости меньше $4 \mathrm{~km} / \mathrm{s}$ и с глубины внедрения $63 \mathrm{~mm}$.

На рис. 2 приведены траектории внедрения в стекло $[5,14]$ и карбид бора низко- и высокомодульного (для сравнения) хрупкого материала. Видно, что излом траектории внедрения в карбид бора наступает раньше, чем в стекле, на уровне $\sim 40 \mathrm{~mm}$ вследствие большей скорости схлопывания откольных фрагментов каверны. Наиболее значительно разнятся траектории проникания после вторичного внедрения по схлопнувшемуся материалу каверны. Для карбида бора показан предполагаемый (недостаток экспериментальных результатов) вариант траектории, состоящей из участков проникания со скоростью $U=f\left(V_{j}\right)$ по уравнению (1) и отсутствия внедрения при расходе хвостовых элементов струи на стенках каверны. Определение значения критической скорости проникания по пересечению траектории и глубины полного поглощения (конечной глубины пробития) становится неопределенным. 
Таблица 1. Свойства исследованных хрупких материалов

\begin{tabular}{|c|c|c|c|c|c|c|c|}
\hline \multirow{2}{*}{$\begin{array}{c}\text { Наименование, размер } \\
\text { пластин материала в mm }\end{array}$} & \multirow{2}{*}{$\begin{array}{l}\text { Плотность, } \\
\mathrm{kg} / \mathrm{m}^{3} \cdot 10^{-3}\end{array}$} & \multicolumn{2}{|c|}{$\begin{array}{c}\text { Скорость упругих } \\
\text { волн, } \mathrm{km} / \mathrm{s}\end{array}$} & \multicolumn{2}{|c|}{$\begin{array}{c}\text { Предел прочности, } \\
\text { GPa }\end{array}$} & \multirow{2}{*}{$\begin{array}{c}\begin{array}{c}\text { Динамическое } \\
\text { сопротивление, GPa }\end{array} \\
R_{t}\end{array}$} & \multirow{2}{*}{$\begin{array}{c}\begin{array}{c}\text { Коэффициент } \\
\text { замещения по стали }\end{array} \\
K_{\mathrm{ef}}\end{array}$} \\
\hline & & $C_{1}$ & $C_{t}$ & на сжатие & к изгибу & & \\
\hline $\begin{array}{l}\text { Карбид бора } 90 \times 90 \times 7.5 \text {, } \\
100 \times 100 \times 18\end{array}$ & 2.52 & 14 & 8.8 & 2.0 & $0.42-0.44$ & 10 & 3.6 \\
\hline $\begin{array}{l}\text { Кароид кремния } \\
100 \times 100 \times 15\end{array}$ & 3.05 & 115 & 7.0 & - & 0.28 & - & 31 \\
\hline Карбид кремния & & & & & & & \\
\hline $\begin{array}{l}\text { С-2 } 80 \times 80 \times 20 \\
\text { Корунд АЛ1 }\end{array}$ & 2.98 & 11.1 & 6.8 & 1.2 & 0.15 & 5 & 2.4 \\
\hline $\begin{array}{l}100 \times 100 \times 12 \\
\text { Ситалл СТЛ-10 }\end{array}$ & 3.88 & 10.3 & 5.6 & 2.4 & 0.19 & 7 & 2.7 \\
\hline $\begin{array}{l}80 \times 80 \times 30 \\
\text { Стекло PG }\end{array}$ & 2.45 & 6.3 & 3.7 & 1.3 & 0.3 & 6 & 3.4 \\
\hline $80 \times 80 \times 10$ & 2.5 & 5.9 & 3.6 & 0.75 & 0.15 & 5 & 2.4 \\
\hline Гранит ${ }^{*}$ & 2.7 & - & - & 0.06 & - & - & 1.5 \\
\hline Бетон ${ }^{*}$ & 2.1 & - & - & 0.04 & - & - & 1.2 \\
\hline Песок* & 1.5 & - & - & 0 & - & - & 1 \\
\hline
\end{tabular}

Примечание: $*-$ из данных по пробитию неограниченной среды.

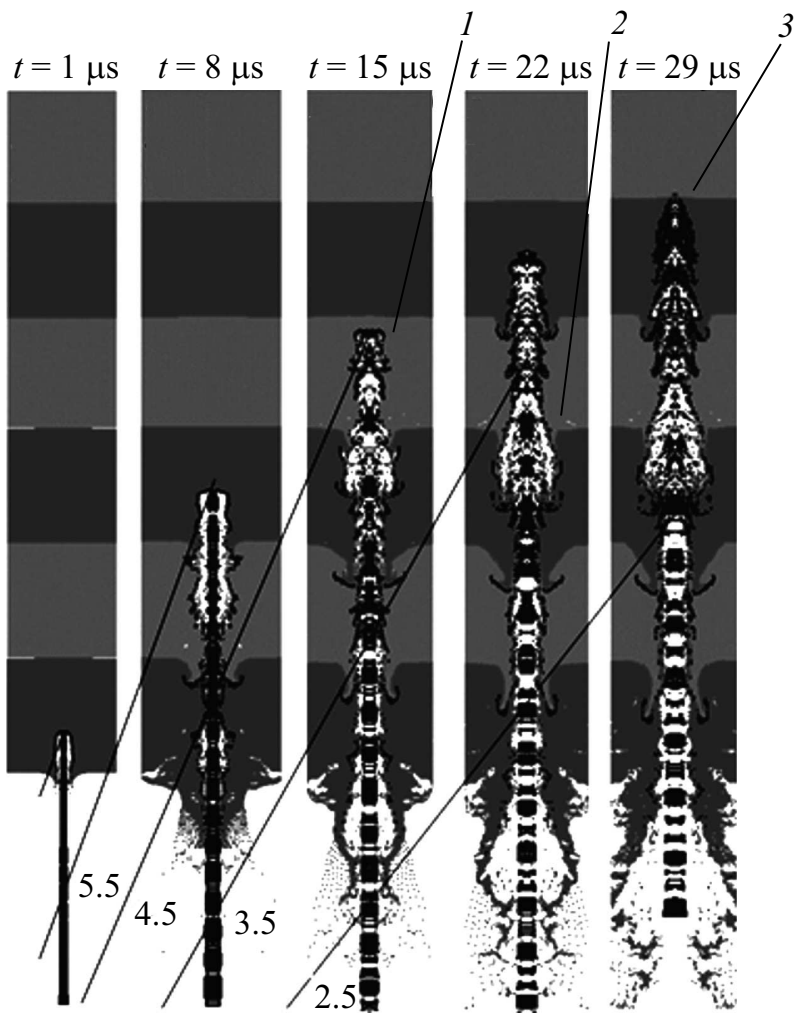

Рис. 3. Отображение результатов моделирования внедрения струи в преграду из пластин карбида кремния $10 \times 80 \times 80 \mathrm{~mm}$ на моменты времени 1, 8, 15, 22 и $29 \mu \mathrm{s}$ [18]: 1 - окончание гидродинамического внедрения; 2 - область диспергирования элементов струи; 3 - накопление массы струи на дне каверны. Наклонные прямые - траектории элементов струи с обозначением скорости движения в $\mathrm{km} / \mathrm{s}$.

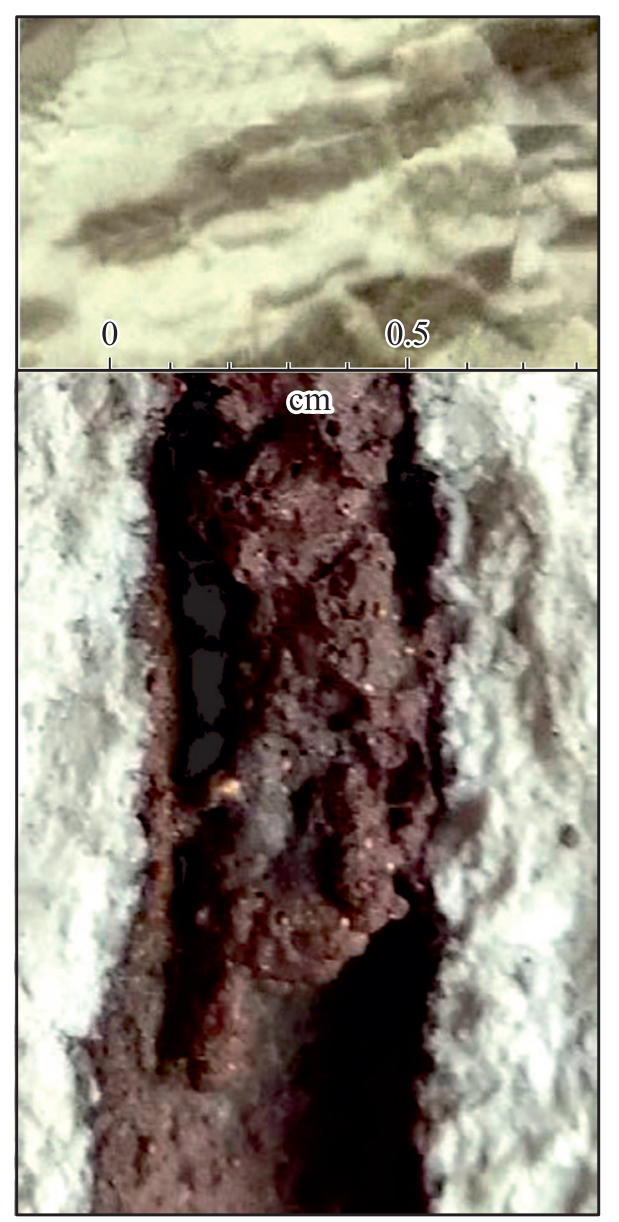

Рис. 4. Сохраненная часть каверны от внедрения высокоскоростной струи в корунд. 
Таблица 2. Тепловые свойства меди

\begin{tabular}{|c|c|c|c|c|}
\hline \multicolumn{2}{|c|}{ Температура, ${ }^{\circ} \mathrm{C}$} & \multicolumn{2}{|c|}{ Теплота, $\mathrm{J} / \mathrm{kg} \cdot 10^{-6}$} & \multirow{2}{*}{$\begin{array}{l}\text { Теплоемкость, } \\
\mathrm{J} /(\text { kggrad }) \cdot 10^{-3}\end{array}$} \\
\hline Плавления & Испарения & Плавления & Испарения & \\
\hline 1083 & 2877 & 0.206 & 4.82 & 0.389 \\
\hline
\end{tabular}

Увеличение и разброс экспериментальных времен внедрения свидетельствует о значительной дестабилизации хвостовых элементов струи, значительная доля которых не участвует в увеличении глубины пробития. Спонтанный характер дестабилизации струи при взаимодействии с каверной в ХМ не позволяет в рамках осевого гидродинамического описания предсказать окончание проникания.

Кроме склонности струи к разрыву на отдельные элементы при растяжении $[2,4,15,17]$ радиальное действие каверны вызывает возмущение [11] и диспергирование участков струи, усиление взаимодействия со стенками каверны. Результаты численного моделирования действия струи с вышеприведенными параметрами [18] показывают, что внедрение в керамики может привести к плавлению и испарению элементов струи, к потере способности хвостовых элементов к прониканию (рис. 3).

Об испарении элементов струи при внедрении в стекло свидетельствуют результаты работы [6], где был сохранен и исследован материал, заполняющий каверну „red glass“, состоящий из смеси медных частиц от $2 \mathrm{~mm}$ до сфер микронного размера и пористой массы стекла, содержащей до $5 \%$ меди. Пористость стеклянной массы и наличие мелких медных сфер авторы объясняют конденсацией паров меди.

На рис. 4 приведен снимок поверхности каверны в корунд после действия струи. Видны мелкие медные сферы, образованные при конденсации испаренной меди, на поверхности вспененной массы смеси меди и корунда.

Как следует из тепловых параметров меди [19], приведенных в табл. 2, минимальная кинетическая энергия, необходимая для плавления и нагрева до $3000 \mathrm{~K}$, равна примерно $1.4 \cdot 10^{6} \mathrm{~J} / \mathrm{kg}$, что соответствует скоростям струи более $3.5 \mathrm{~km} / \mathrm{s}$. С учетом малого времени разгрузки ударно-сжатой меди из зоны внедрения в хрупкий материал энергии для испарения элементов струи достаточно.

\section{Эффективность поглощения высокоскоростной струи хрупким материалом}

В связи с дестабилизацией внедрения ВСС в хрупких материалах прогноз полного поглощения затруднен. Для решения этой задачи рассмотрим составную преграду, состоящую из слоев ХМ и стали. Наличие стального основания продиктовано возможностью фиксирования конечной глубины пробития преграды и доступностью материала.

Из баланса расхода одинаковой струи по стали и комбинированной преграде, состоящей из слоев керамики и стали, можно написать

$$
L_{s t} /\left(L_{0}-L_{f}\right)=1-K_{\mathrm{ef}}\left(\rho_{b m} / \rho_{\mathrm{st}}\right)^{0.5} L_{b m} /\left(L_{0}-L_{f}\right),
$$

где $\rho_{b m}, \rho_{\mathrm{st}}-$ плотности хрупкого материала и стали соответственно; $K_{\text {eff }}$ - коэффициент эффективности отличия расхода струи от гидродинамического соотношения плотностей $[2,15] ; L_{0}, L_{e}=L_{f}+L_{b m}+L_{\mathrm{st}}-$ глубины пробития стали и составной преграды со слоем хрупкого материала $L_{b m} ; L_{f}$ - толщина лицевого слоя стали, в случае его применения.

На вставке рис. 5 приведены результаты по определению глубины пробития комбинированной преграды хрупкий материал-сталь при различной толщине слоя карбида бора и стекла. Толщина слоя ХМ при отсутствии каверны в стали принималась за глубину полного поглощения КС при данном поперечном размере $B$ слоя ХМ. Видно, что применение хрупких материалов позволяет уменьшить глубину полного поглощения ВСС по сравнению со сталью. Причем наибольшее снижение толщины комбинированной преграды наблюдается при определенном слое хрупкого материала. Аналогичный

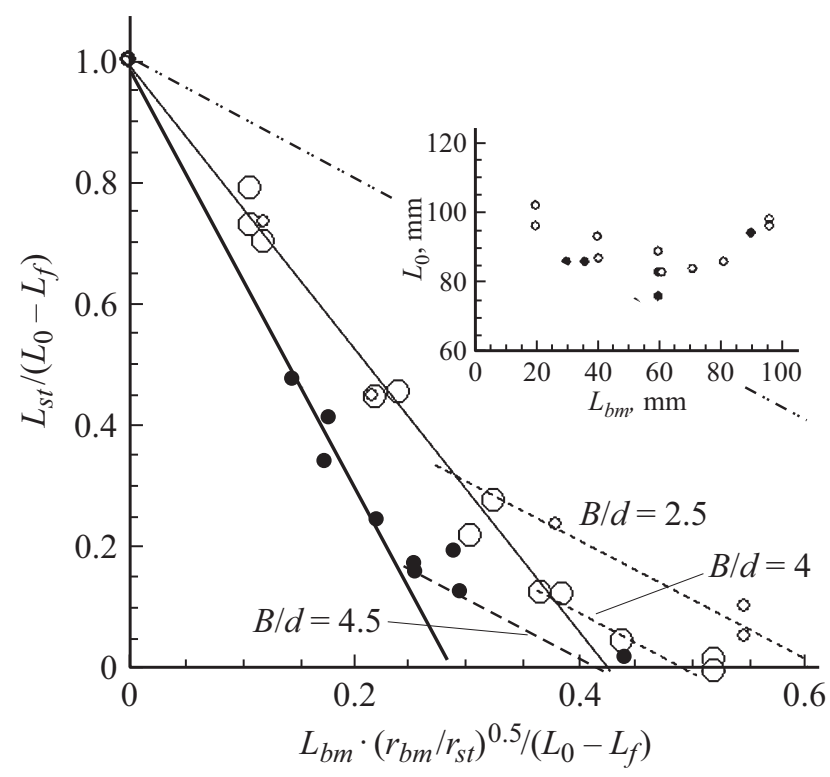

Рис. 5. Остаточное пробитие стального фиксирующего слоя в зависимости от толщины слоя хрупкого материала: О для стекла (размер точки отражает величину $B / d$ ); • - для карбида бора в приведенных координатах. Сплошные линии участки эффективного поглощение КС (тонкая в стекле, толстая - в карбиде бора). Штриховые линии - поглощение в области разгрузки, штрихпунктирная линия - гидродинамический эквивалент замещения стали хрупким материалом. $B-$ поперечный размер пластины хрупкого материала. На вставке приведено изменение глубины пробития комбинированной преграды в зависимости от толщины слоя хрупкого материала с поперечным размером $B=80-90 \mathrm{~mm}$. 


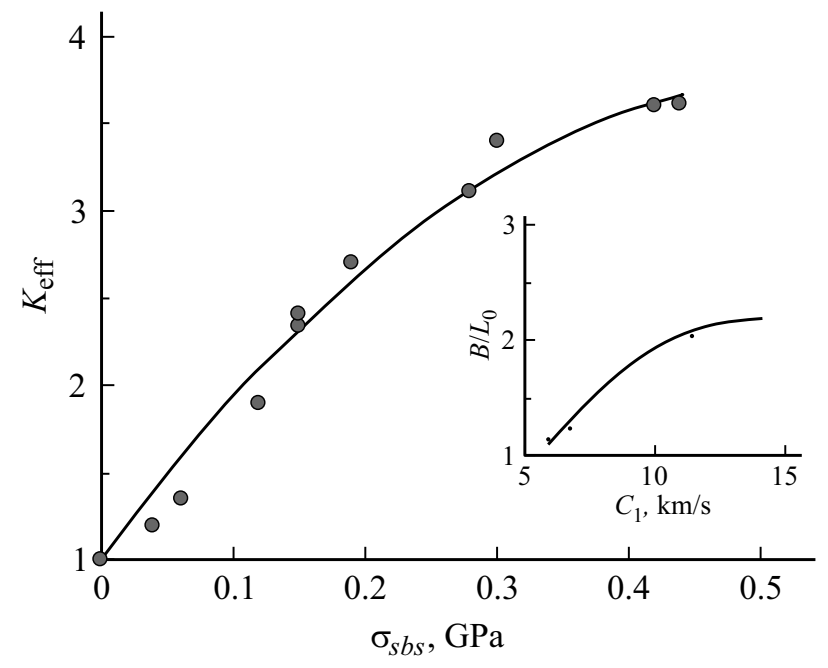

Рис. 6. Зависимость коэффициента эффективности струегашения хрупких материалов от предела прочности на изгиб (по данным табл. 1). Вставка - зависимость поперечного размера пластины хрупкого материала $B$, обеспечивающего полное струегашение, от скорости звука.

качественный результат воспроизводится для всех хрупких материалов [7,14,20,21].

Анализ результатов пробития составной преграды $\mathrm{XM-сталь} \mathrm{позволяет} \mathrm{оценить} \mathrm{эффективность} \mathrm{поглоще-}$ ния ВВС в ХМ. Из уравнения (2) следует, что толщина остаточного слоя стали линейно зависит от толщины слоя хрупкого материала. На рис. 5 результаты пробития комбинированной преграды приводятся в приведенных координатах согласно уравнению (2). Результаты по остальным хрупким материалам аналогичны и отражены в $[5,13,14]$.

Видно, что до определенной толщины хрупкого материала экспериментальные результаты по замещению стали описываются уравнением с коэффициентом эффективности $K_{\mathrm{ef}}>1$ (табл. 1 ).

По результатам определения $K_{\mathrm{eff}}$ струегашения различных хрупких материалов построена зависимость от предела прочности на изгиб (рис. 6), которая наиболее адекватно описывает экспериментальные результаты [20]. Предел прочности на изгиб является основной характеристикой прочности ХМ наряду с прочностью на сжатие и твердостью. Выбор определяющей характеристики обусловлен подобием нагружения при определении прочности к изгибу и деформирования материала в зоне внедрения.

Высокие прочностные характеристики карбида бора проявляются в наибольшем коэффициенте струегашения по сравнению со стеклом, карбидом кремния и корундом. Высокие показатели ситалла, отмеченные также в [2], по-видимому, определяются сочетанием кристаллической (наполнитель - корунд) и аморфной (связующее - стекло) фаз и требуют дополнительного анализа.
Эффективное струегашение нарушается при больших толщинах хрупкого материала вследствие влияния боковой волны разгрузки. При увеличении толщины хрупкого материала замещение начинает идти в соответствии с гидродинамическим соотношением плотностей (штриховые линии параллельны штрихпунктирной линии, построенной при $\left.K_{\text {eff }}=1\right)$ и общий габарит преграды начинает увеличиваться (вставка на рис. 5). Это связано с тем, что с определенного момента боковая волна разгрузки опережает зону внедрения. После опережения области внедрения кумулятивной струи волной разгрузки от боковой свободной поверхности ХМ начинается процесс разрушения материала, нагруженного в волне сжатия, распространяющейся с начала внедрения (дозвуковой режим внедрения). Материал теряет прочность, последующее внедрение в него идет в гидродинамическом режиме. При достаточных поперечных размерах $B$ изделий из ХМ реализуется полное струегашение в минимальной толщине и массе защиты (вставка на рис. 6). Видно, что высокопрочные керамики с высокой скоростью звука обеспечивают полное струегашение при $B / L_{0} \sim 2$, а литьевые стекло и ситалл - при $B / L_{0} \sim 1$.

Высокая скорость боковой волны разгрузки маскирует внедрение дестабилизированной КС. При не оправданных с практической точки зрения больших поперечных размерах слоя ХМ, эксперимент демонстрирует сохранение высокой эффективности струегашения вплоть до полного поглощения ВВС.

Таким образом, появилась возможность оценки толщины и массы защиты из высокопрочных хрупких материалов при действии ВСС различной длины с уровнем пробития по стали $L_{0}$.

\section{Заключение}

Взаимодействие высокоскоростной металлической струи при скоростях более $4 \mathrm{~km} / \mathrm{s}$ с хрупким материалом приводит к деградации струи и дестабилизации внедрения, появлению новых факторов, которые не могут быть учтены в рамках гидродинамического одномерного приближения.

Тем не менее выявления особенностей отклонения от гидродинамического приближения позволяют глубже понять физические процессы, сопровождающие взаимодействие конденсированных сред при экстремальных условиях.

Эмпирический подход сопоставления экспериментального результата по действию на комбинацию ХМ-сталь с гидродинамическим струйным приближением $[1,2,15]$ дает возможность прогнозировать полное поглощение высокоскоростной струи.

Благодарю С.А. Душенок, А.И. Михайлина, М.П. Кужеля, А.И. Овсиенко за помощь в материальном обеспечении исследований. 


\section{Список литературы}

[1] Rosenberg Z., Dekel E. Terminal Ballistics. Springer, 2016. P. 359.

[2] Григорян В.А., Белобородько А.Н., Дорохов Н.С. и др. Частные вопросы конечной баллистики / Под ред. В.А. Григоряна. М.: Изд-во МГТУ им. Н.Э. Баумана, 2006. Гл. 5. С. 592.

[3] Held M. // Propell. Explos. Pyrot. 1998. Vol. 23. N 2. P. 105110.

[4] Kozhushko A.A., Kozachuk A.I., Rumyantsev B.V., Sinani A.B., Vlasov A.S., Zilberbrand E.L. // Int. J. Impact Eng. 2003. N 29. P. 385-390.

[5] Румяниев Б.В. // ЖТФ. 2009. Т. 79. Вып. 6. С. 28-32. [Rumyantsev B.V. // Techn. Phys. 2009. Vol. 54. N 6. P. 790794.]

[6] Hauver G.E., Netherwood P.H., Bensk R.F., Melani A. // Technical report BRL-TR-3273. www.dtic.mil/dtic/tr/fulltext/u2/a243520.pdf

[7] Hornemann U., Holzwarth A. // Int. J. Impact Eng. 1997. Vol. 20. P. 375.

[8] Moran B., Glenn L.A., Kusubov A. // J. Phys. III. 1991. Vol. 1. P. 147.

[9] Xie Y.-L., Liu H.-W., Zhang Y. // Proc. of the Int. Conf. on Applied Mathematics and Mechanics (ICAMM 2016). Bangkok, Thailand, 2016. P. 173-176.

[10] Лазарев В.Б., Баланкин А.С., Изотов А.Д., Кожушко А.А. Структурная устойчивость и динамическая прочность неорганических материалов. М.: Наука, 1993. 175 с.

[11] Ahderson Ch.E., Hohler V., Walker J.D., Stilp A.J. // Proc. of the 14th Intern. Symposium on Ballistics. Quebec, Canada, 1993. P. 145-154.

[12] Kozhushko A.A., Kozachuk A.L., Rumyantsev B.V., Sinani A.B., Vlasov A.S. // Proc. of the $20^{\text {th }}$ Intern. Symposium on Ballistics. Orlando, FL, USA, 2002. P. 988-995.

[13] Румянщев Б.В. // ФТТ. 2011. Т. 53. Вып. 10. С. 2018-2022.

[14] Румянщев Б.В. // Тр. междунар. конф. „ХІ Харитоновские тематические научные чтения“. Саров: РФЯЦ-ВНИИЭФ, 2009. C. 505.

[15] Андреев С.Г., Бабкин А.В., Баум Ф.А. и др. Физика взрыва / Под ред. Л.П. Орленко. М.: Физматлит, 2002. Т. 2. С. 238.

[16] Савиных А.С., Гаркуиин Г.В., Разоренов С.В., Румянцев В.И. // ЖТФ. 2015. Т. 85. Вып. 6. С. 77-82.

[17] Hirsh E.A. // Propellants Explos. 1979. Vol. 4. N 14. P. 89-94.

[18] Rumyantsev B.V., Klimenko V.Yu. // AIP Conf. Proc. 2012. Vol. 1426. P. 56-59.

[19] Таблищы физических величин. Справочник / Под ред. И.К. Кикоина. М.: Атомиздат, 1976. С. 1006.

[20] Hornemann $U$. // Proc. of the $11^{\text {th }}$ Int. symposium on Ballistics. 1989. Vol. II. 381-38.

[21] Румянщев Б.В. // Письма ЖТФ. 2016. Т. 42. Вып. 17. C. $87-94$. 